\title{
THE EFFECT OF MINDFULNESS ON ACADEMIC SELF- EFFICACY: A RANDOMISED CONTROLLED TRIAL
}

\author{
Jack R. Menges ${ }^{1}$ \\ Psychology, College of Healthcare Sciences, \\ Division of Tropical Health \& Medicine, James Cook University, Australia \\ (Email: jack.menges@jcu.edu.au) \\ Marie L. Caltabiano ${ }^{2}$ \\ Psychology, College of Healthcare Sciences, \\ Division of Tropical Health \& Medicine, James Cook University, Australia \\ (Email: marie.caltabiano@jcu.edu.au)
}

Accepted date: $15-04-2019$

Published date:07-07-2019

To cite this document: Menges, J. R. \& Caltabiano, M. L. (2019). The Effect Of Mindfulness on Academic Self-Efficacy: A Randomised Controlled Trial. International Journal of Education, Psychology and Counseling, 4(31), 170-186.

DOI:10.35631/IJEPC.4310015

Abstract: This study examined the effect of a brief mindfulness intervention on academic selfefficacy. Twenty-six university students were randomised to a four day brief mindfulness intervention or a wait-listed control condition. The brief mindfulness intervention took the form of four 30 minute sessions of mindfulness meditation over four consecutive days. Measures of mindfulness, emotional wellbeing and academic self-efficacy were obtained via a self-report survey prior to the intervention, post-intervention and at one month follow-up. Both groups had comparable baseline measures on all three scales. Data analysis revealed that both academic self-efficacy and mindfulness increased between pre- and post-intervention with a medium effect size $(d=0.472$ and 0.415 respectively). Emotional wellbeing significantly increased following the intervention with a large effect size $(d=0.652)$ and remained at this level after one month. Academic self-efficacy also stayed at elevated post-intervention levels after one month while mindfulness continued to increase following the intervention and was significantly higher at follow-up than at baseline $(d=0.564)$. There were no significant changes in the measured variables for the control group. Regression analysis revealed that increases in emotional wellbeing significantly predicted increases in academic self-efficacy for participants in the experimental group, both increases in mindfulness and emotional wellbeing were significantly correlated with increases in academic self-efficacy. These findings suggest that a brief mindfulness intervention is an effective and practical means to improve academic self-efficacy and emotional wellbeing in university students. Implications, limitations and future directions for research are discussed. 
Keywords: Mindfulness, Self-Efficacy, Academic, Emotional Wellbeing, Meditation, Brief Intervention

\section{Introduction}

Attending university can be some of the most challenging and stressful years of a person's life. Achieving to the best of one's ability and persevering through this difficult time is essential as there is a substantial body of research linking educational attainment to major life outcomes including physical health, mental health, interpersonal relationships and income (Brack, Van De Straat \& Missinne, 2014; Chan, 2016; Chiu, Hayward \& Saito, 2016; Hahn \& Truman, 2015; Walsemann, Gee \& Ro, 2013). As such, exploring means of supporting students to achieve better results at university and stave off negative outcomes, such as dropping out, have become critical facets of research in the humanities field.

\section{Literature Review}

\section{Academic Self-efficacy}

Self-efficacy is the central component through which a person is motivated to take action or exercise agency (Bandura, 1999). A significant predictor of academic outcomes and achievement is academic self-efficacy (Caprara et al., 2008; Honicke \& Broadbent, 2016). Schunk (1991) defines academic self-efficacy as an individual's confidence in their ability to successfully perform academic tasks at a designated level. More broadly, Bandura, Barbaranelli, Caprara and Pastorelli (2001) state that academic self-efficacy is an individual's self-efficacy concerning regulation of learning and thus mastery of academia. Academic self-efficacy has a positive effect on educational progress and success as well as career choice and overall aspirations (Bandura et al., 2001). Individuals are less likely to focus on more difficult or complex career goals if they lack academic self-efficacy and as such lower self-belief in this area can have profound life-long impact.

While there are many studies reinforcing the view that self-efficacy has a significant impact on educational outcomes, there are a limited number of studies actually measuring the effectiveness of interventions aimed at improving self-efficacy in an academic and learning context (Unrau et al., 2018). The theoretical framework for this study is Bandura's (1977) theory of self-efficacy. Bandura's theory suggests that there are four primary sources via which a person's self-efficacy can be enhanced. These are, mastery experiences, vicarious experiences, verbal and social persuasion, and emotional and physiological states. Of these sources, the improvement of an individual's emotional state is one of the least explored means to improve self-efficacy (Unrau et al., 2018). Recent interventions which have aimed to improve academic self-efficacy have done so via vicarious experience (Bartsch, Case \& Meerman, 2012), mastery experience (Spedding, Hawkes \& Burgess, 2017; Perry, DeWine, Duffy \& Vance, 2007; Cambridge-Williams, Winsler, Kitsantas \& Bernard, 2013; Panadero, Jonsson \& Botella, 2017) and verbal or social persuasion (Spedding et al., 2017). No studies have tested an intervention directly aimed at improving the emotional state of students in order to effect an improvement in academic self-efficacy as is the goal in the present experiment. 


\section{Mindfulness}

Mindfulness, or a mindful state, is defined as "being in the present moment on purpose" (KabatZinn, 1990 p. 29) and has been explored as an alternative means of promoting positive academic outcomes and in respect to a potential relationship with academic self-efficacy or self-efficacy in students Spedding et al., 2017; Panadoro et al., 2017). For the purpose of this study, levels of mindfulness are defined as an individual's capacity to remain in a mindful state and to do so for longer periods of time; a capacity that increases with mindfulness practice (Kabat-Zinn, 1990).

Mindfulness practice is regularly hypothesised as a means to reduce stress and anxiety for students (Messer, Horan, Turner \& Weber, 2016; Chiesa \& Serretti, 2009). In undergraduate students, mindfulness practice is linked to reduced stress, depression and anxiety when compared to a control group and alternate interventions such as physical exercise (Gallego, Aguilar-Parra, Cangas, Langer \& Manas, 2014). Palomino (2017) argues that a mindfulness intervention is an effective means to improve academic self-concept (an individual's perception of themselves in academic situations) in students in order to improve self-esteem and academic outcomes. Mindfulness practice has been linked with improved test performance (Mrazek, Franklin, Phillips, Baird \& Schooler, 2013) and retention of lecture material (Ramsburg \& Youmans, 2014). Mindfulness has also been positively correlated with academic self-efficacy as mediated by positive reappraisal when following a perceived academic failure (Hanley, Palejwala, Hanley Canto \& Garland, 2015).

There is a large body of literature demonstrating a link between mindfulness practice and psychological, emotional, physical, social and neurological changes (Baer, Smith, Hopkins, Krietemeyer \& Toney, 2006; Blanck et al., 2018; Chambers, Gullone \& Allen, 2009; Crescentini \& Capurso, 2015; Sulphey, 2016; Walach, Buchheld, Buttenmuller, Kleinknecht \& Schmidt, 2006). Higher levels of mindfulness are significantly correlated with multiple indicators of emotional wellbeing and positive mental health including lower levels of depression, reduced anxiety, reduced stress, lower negative affect, higher positive affect and higher life satisfaction (Brown \& Ryan, 2003). Higher levels of mindfulness are also associated with lower levels of dissociation, neuroticism and psychological distress and higher levels of emotional intelligence and extroversion (Baer et al., 2006; Walach et al., 2006), traits that are linked with higher levels of emotional wellbeing (Sanchez-Alvarez, Extremera \& Fernandez-Berrocal, 2016). Higher levels of mindfulness have been shown to improve emotional wellbeing both directly (Splevins, Smith \& Simpson, 2009) and via more effective stress management and coping strategies (Weinstein, Brown \& Ryan, 2009). Higher levels of mindfulness have also been shown to be linked with reduced negative affect and more positive thought patterns (Andrews-Hanna et al., 2013).

Consistently, mindfulness practice is linked with constructs such as improved meta-cognition, acceptance, reduced attachment, improved coping and improved management of negative feelings and emotions (for example, physical pain or ruminative thought patterns); as such, the individuals' concept of self, behaviour and perception, via increased mindfulness, becomes less controlled by external stimuli (Sulphey, 2016; Crescentini \& Capurso, 2015). Thus the concepts of mindfulness and self-efficacy, defined as the combination of self-concept and an internal locus of control (the belief that you have control over your life and actions and that you are responsible for your successes) (Cervone, 2000), converge. Hodgins and Knee (2002) argue that those who 
are higher in openness to honest moment to moment experience (which they identify as being similar to mindfulness) may have a greater capacity for autonomous self-regulation and selfdetermination of behaviour, or in essence a more internal locus of control. Mindfulness predicts higher self-awareness and self-regulated behaviour (Brown \& Ryan, 2003) and is correlated with improved self-esteem and reduced social anxiety (Rasmussen \& Pidgeon, 2011). Similarly to self-efficacy, which is positively correlated with greater task persistence despite difficulty or setbacks (Bandura, 1977), mindfulness may increase task persistence via an increase in distress tolerance (Carpenter, Sanford \& Hofmann, 2019). The mechanism by which mindfulness effectively reduces stress and increases capacity to deal with and manage stress, has been argued to be its capacity to allow people to find meaning in adversity and to be more comfortable with that adversity or difficulty (Garland, Hanley, Baker \& Howard, 2017). In respect to academic self-efficacy, uncertainty is a major factor. When academic self-efficacy is low it indicates that the student is uncertain about their capacity to complete set tasks (Schunk, 1991). Mindfulness has been shown to moderate the relationship between uncertainty and negative affect, in that more mindful individuals experience less negative affect as a result of feeling uncertain (Haddock, Foad, Windson-Shellard, Dummel \& Adarves-Yorno, 2017). Mindful individuals are more comfortable with the 'not knowing' or being unsure of an outcome (for example, an exam), which may result in reduced levels of stress, reduced feelings of uncertainty and increased selfefficacy in an academic context.

As discussed previously, increased mindfulness is significantly correlated with an improved emotional state and thus, according to self-efficacy theory, should be an effective means to improve academic self-efficacy (Pradhan et al., 2007; Zautra et al., 2008; Sanchez-Alvarez et al., 2016). Additionally, a mindfulness intervention is low cost, requires minimal time investment on the part of the student and minimal resource investment on the part of the institution (Messer et al., 2016) while also being flexible in that it can optionally be utilised as part of a larger intervention designed to increase academic self-efficacy by utilising more of the primary sources identified in self-efficacy theory for greater overall effect (Unrau et al, 2018). There is evidence to suggest that academic self-efficacy may be improved by increased perceived social support (Reich, Bickman \& Heflinger, 2004; Oliver et al., 2017) and as such perceived social support will be controlled for in the present study.

In summary, self-efficacy theory (Bandura, 1977) states that improvements in emotional state are an effective way to improve an individual's self-efficacy. A review of the current literature indicates that there have been no recent trials of interventions aimed at improving academic selfefficacy via an improvement in emotional state (Unrau et al., 2018). This is quite significant as academic self-efficacy is a critical factor in predicting achievement for university students (Caprara et al., 2008) and an intervention which is able to increase academic self-efficacy by improving the emotional state of students could be employed in conjunction with other avenues of intervention for a greater cumulative effect (Unrau et al., 2018). Mindfulness has been identified as an effective, cheap, easy and practical means by which to improve an individual's emotional state (Harris, Jennings, Katz, Abenavoli \& Greenberg, 2016).

\section{Study Aim and Hypothesis}

The purpose of this study is to examine, through a randomised controlled trial, whether or not a brief mindfulness intervention will be effective at improving the academic self-efficacy of a 
group of university students via an increase in their emotional wellbeing. The theoretical framework for this study is Bandura's (1977) theory of self-efficacy, which suggests that such an intervention should be effective for this purpose. The brief mindfulness intervention in this study will be operationalised in a manner similar to that utilised in Mindfulness Based Stress Reduction therapy (Kabat-Zinn, 1990), that is, participants will focus on their breathing and bodily sensations. The intervention is short in duration, occurring for thirty minutes each day for four consecutive days. Interventions of this brief duration have been shown previously to be effective at producing significant changes in participants (Tang et al., 2007). There are several gaps in the literature which will be explored in the present study, notably the direct relationship of brief mindfulness practice on levels of academic self-efficacy (Sampl, Maran \& Furtner, 2017) and how effective such an intervention can be in maintaining changes over time via a follow-up measure (Gallego et al., 2014). It was hypothesised that participants in the mindfulness intervention group would have significantly increased mindfulness, emotional wellbeing and academic self-efficacy following the trial and that part of the positive effect of mindfulness on academic self-efficacy would be explained by the mediating effect of increased emotional wellbeing (see the proposed model illustrated in Figure 1).

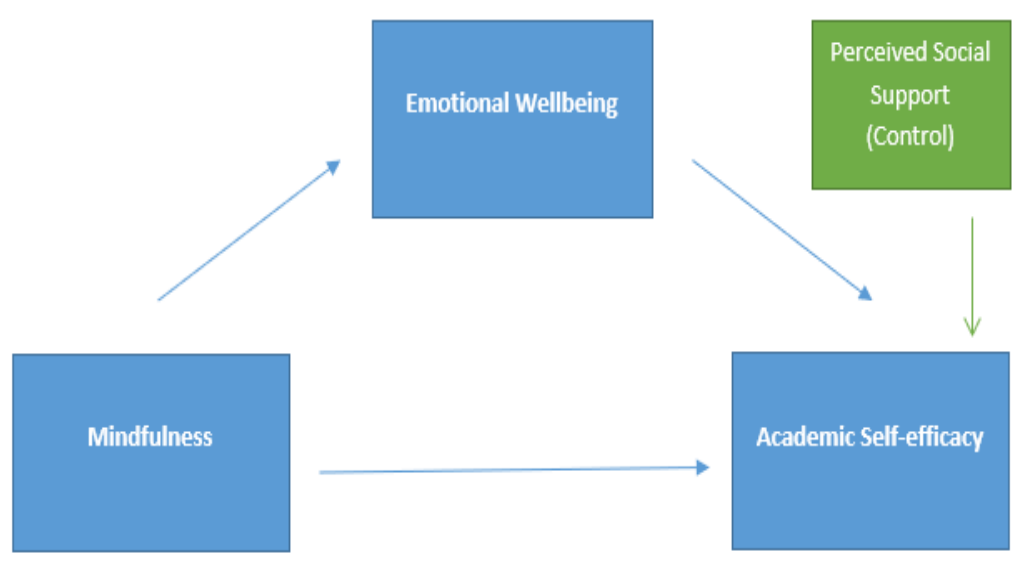

Figure 1: Hypothesised Relationships Between Variables|

\section{Methodology}

\section{Participants}

Forty participants were sought for the study, twenty per group, to allow for adequate statistical power. Thirty participants volunteered for the study, two failed to complete the pre-intervention survey within the required timeframe, one failed to complete the post-intervention survey within the required timeframe and one participant in the control condition reported that they had inadvertently attended one of the mindfulness sessions and as such were removed from the study. 
In total 26 participants provided usable data. These participants were university students with a mean age of 27.15 years $(S D=10.89), 20$ were female. The inclusion criteria were that participants had to be currently enrolled university students who had the ability to participate in the study on the James Cook University Cairns campus for four consecutive days. There were no exclusion criteria.

Participants were initially randomly allocated to either the experimental or wait-listed control conditions such that there were 15 participants in each group. The experimental condition had 12 females with a mean age of 26.13 years $(S D=10)$. The wait-listed control condition had 8 females (4 of 15 participants were removed from the control group due to not providing usable data) with a mean age of 28.55 years $(S D=12.37)$.

Regardless of group allocation, participants were provided with a link to complete the online preintervention survey three days prior to the intervention commencing with instructions to complete the survey before the brief mindfulness intervention started. The survey was distributed using the 'Qualtrics' online survey platform.

The Brief Mindfulness Intervention took place for 30 minutes per day for four consecutive days from Monday $6^{\text {th }}$ August 2018 to Thursday $9^{\text {th }}$ August 2018. The intervention took place on all four days in a large room at the James Cook University Cairns campus library. The room was dimly lit and quiet for the purpose of facilitating mindfulness meditation. Sessions were facilitated by two staff from the James Cook University Wellness Centre both of whom have extensive experience facilitating group meditation and mindfulness sessions. A script was used by the facilitators during the mindfulness meditation sessions which involved coaching participants to focus on their breathing and bodily sensations (known as body scanning). Participants were advised prior to attending that during sessions they were able to disengage from the activity or leave the room if they needed.

Following completion of the fourth and final mindfulness meditation session a link to the postintervention survey (identical to the pre-intervention survey other than random ordering of questions) was emailed to all participants with instructions to complete the survey as soon as able within a maximum of 24 hours. Survey question order was randomised to minimise a potential practice effect and familiarity. One month following the completion of the intervention a link to the same survey was emailed to the experimental condition participants to complete as a follow-up measure.

\section{Measures}

\section{Mindfulness}

Mindfulness was measured using the Mindfulness Attention Awareness Scale (MAAS) (Brown \& Ryan, 2003). The MAAS is a 15 item scale that assesses the core characteristics of mindfulness, that is, an individual's awareness and attention to what is taking place in the present moment. Participants respond on a 6-point Likert scale indicating how frequently they currently have each of the experiences outlined in the items $(1=$ 'almost always' to $6=$ 'almost never'). The MAAS has been used extensively in student populations, has high test re-test reliability (Brown \& Ryan, 2003) and in the current sample had a Cronbach's alpha of .75 at the preintervention and .88 at the post-intervention measure. Higher scores indicate higher levels of 
mindfulness. An example item is "I rush through activities without being really attentive to them".

\section{Wellbeing}

Wellbeing was measured using the Warwick-Edinburgh Mental Well-being Scale (WEMWBS) (Tennant et al., 2007). The WEMWBS is a 14 item scale that assesses mental and emotional wellbeing. Participants respond on a 5-point Likert scale indicating how often an item is true for them over the past week ( $1=$ 'all of the time' to $5=$ 'none of the time'). The scale covers hedonic and eudainomic aspects of wellbeing, positive affect and positive functioning. WEMWBS has high internal consistency and reliability and is less prone to social desirability bias than other comparable scales (Tennant et al., 2007). The Cronbach's alpha in the present study was .89 at the pre-intervention and .92 at the post-intervention measure. Higher scores indicate less positive mental and emotional wellbeing; scores were recoded so that higher scores indicated better mental and emotional wellbeing. An example item is "I've been feeling optimistic about the future".

\section{Perceived Social Support}

Perceived Social Support was measured using the Multidimensional Scale of Perceived Social Support (MSPSS) (Zimet et al., 1988). The MSPSS is a 12 item scale that assesses three factors of perceived social support, family, friends and significant other. Participants respond on a 7point Likert scale that is positively worded in terms of how strongly participants agree with each statement ( 1 = 'strongly agree to $7=$ 'strongly disagree'). Higher scores indicate lower levels of perceived social support, scores were recoded so that higher scores indicated higher levels of perceived social support. The MSPSS is brief, has high internal validity and good test re-test reliability (Zimet et al., 1988) with a Cronbach's alpha in the present study of .91 at the pre- and post-intervention measures. An example item is "My friends really try to help me".

\section{Academic Self-Efficacy}

Academic self-efficacy was measured using the Academic Self-Efficacy Scale developed by Zajacova, Lynch and Espenshade (2005). This scale has 27 items and is designed specifically for use with university students. Participants respond on a 10-point Likert scale indicating how confident they feel in successfully completing a number of university tasks. Responses range from 'not at all confident' (1) to 'extremely confident' (10) with higher scores indicating greater academic self-efficacy. Four items were not deemed relevant to the present study and were removed. Twenty-three of the 27 total items were used. The scale has high reliability (Zajacova et al., 2005), in the present study the Cronbach's alpha was .95 at the pre-intervention and .97 at the post-intervention assessment. An example item for participants to rate their confidence on is "Writing assignments".

\section{Data Analysis}

All data analysis was conducted via the software program the 'Statistical Package for the Social Sciences' version 25 (IBM SPSS 25). Levene's test was used to confirm equality of variances for the data between the groups. 1 sample K-S tests and P-P plots were used to confirm normal distributions for the data. Box plots were used to look for any potential outliers in the data set; none were found. If required, data was recoded so that higher scores indicated higher levels of each construct. 
Paired samples t-tests were used to test for pre and post differences within groups. Perceived social support was averaged between the pre and post measures and was found to not be correlated with academic self-efficacy $(r=.26, p=.354)$ and as such was not included in further data analysis.

Paired samples t-tests were used to find if there were significant changes in mindfulness, emotional wellbeing and academic self-efficacy for the experimental and control group's between pre-intervention, post-intervention and follow-up measures. Regression analysis was used to determine if increases in mindfulness predicted increases in academic self-efficacy via a mediating effect of increased emotional wellbeing. Correlation, frequency and descriptive statistics were also obtained.

\section{Results}

There was no significant difference between the experimental and control groups' baseline mindfulness $(t(24)=-.24, p=.74)$, emotional wellbeing $(t(24)=.97, p=.343)$ or academic selfefficacy $(t(24)=.27, p=.789)$ scores. Descriptive statistics for the scores obtained are presented in Table 1 separated by group and time of measurement.

Table 1: Means and Standard Deviations for Mindfulness, Emotional Wellbeing and Academic Self-Efficacy Scores

\begin{tabular}{|c|c|c|c|c|c|c|c|}
\hline & & \multicolumn{2}{|c|}{ Pre-intervention } & \multicolumn{2}{|c|}{ Post-intervention } & \multicolumn{2}{|c|}{ One month follow-up } \\
\hline & & $\mathrm{M}$ & $\mathrm{SD}$ & $\mathrm{M}$ & SD & $\mathrm{M}$ & SD \\
\hline \multirow{3}{*}{ Experimental } & Mindfulness & 36 & 6.68 & 38.93 & 7.51 & 39.67 & 7.93 \\
\hline & $\begin{array}{l}\text { Academic } \\
\text { Self-efficacy }\end{array}$ & 137.07 & 36.36 & 143.60 & 39.94 & 142.67 & 41.24 \\
\hline & $\begin{array}{l}\text { Emotional } \\
\text { Wellbeing }\end{array}$ & 44.4 & 7.28 & 49 & 9.27 & 48.73 & 8.83 \\
\hline \multirow{3}{*}{ Control } & Mindfulness & 35.36 & 6.99 & 32.45 & 8.48 & & \\
\hline & $\begin{array}{l}\text { Academic } \\
\text { Self-efficacy }\end{array}$ & 140.91 & 34.85 & 146.91 & 42.11 & & \\
\hline & $\begin{array}{l}\text { Emotional } \\
\text { Wellbeing }\end{array}$ & 47.45 & 8.8 & 48 & 7.5 & & \\
\hline
\end{tabular}

Note. $\mathrm{M}=$ Mean, $\mathrm{SD}=$ Standard Deviation

Mindfulness scores for the experimental group did increase from pre-intervention $(M=36, S D=$ $6.68)$ to post-intervention $(M=38.93, S D=7.51)$; this increase was not statistically significant but does represent a moderate effect size, $t(14)=-1.61, p=.131, d=0.415$. Mindfulness continued to increase post-intervention and at one month follow-up had significantly increased from baseline, $t(14)=-2.19, p=.046, d=0.564$. 
There was a significant increase in emotional wellbeing in the experimental group from preintervention $(M=44.4, S D=7.28)$ to post-intervention $(M=49, S D=9.27)$ with a large effect size, $t(14)=-2.52, p=.024, d=0.652$. There was no significant change in emotional wellbeing for the control group during the same period, $t(10)=-0.40, p=.70$. For the experimental group, emotional wellbeing seemingly remained elevated as it did not change significantly from postintervention to one month follow-up $(M=48.73 S D=8.83), t(14)=.25, p=.808, d=-0.064$.

Academic self-efficacy did increase for the experimental group between the pre-intervention $(M$ $=137.07, S D=36.36)$ and post-intervention $(M=143.60, S D=39.94)$, this increase was not significant at the traditional level but does represent a moderate effect size, $t(14)=-1.83, p$ $=.089, d=0.472$. Academic self-efficacy remained relatively constant at one month follow-up $(M=142.67, S D=41.24)$ with no significant change from post-intervention, $t(14)=.27, p$ $=.791, d=-0.07$. It is noted that the control group had a non-significant increase in academic self-efficacy between pre- and post-intervention measures, however this effect was smaller than the effect for the experimental group, $t(10)=-0.84, p=.42, d=0.254$.

Regression analysis (see Table 2) was used to investigate the hypothesis that, in the experimental group, the relationship between mindfulness and academic self-efficacy would be mediated by increased emotional wellbeing. Changes between the pre- and post-intervention scores for the experimental group were used for the analysis. Results indicated that changes in mindfulness and emotional wellbeing explained, in combination, $54.77 \%$ of the variance in changes in academic self-efficacy. The overall model was significant, $R^{2}=.55, F(2,12)=7.26, p<.01$. The independent contribution to the model of changes in mindfulness was not statistically significant, $\mathrm{b}=0.69, t(12)=1.75, p=.106(95 \%$ CI $[-0.17,1.56])$, while the contribution of changes in emotional wellbeing was significant, $\mathrm{b}=1.09, t(12)=2.73, p=.018$ (95\% CI [0.22, 1.95]). Changes in mindfulness also did not have a significant effect on changes in emotional wellbeing, $\mathrm{b}=0.29, t(13)=1.10, p=.29$ (95\% CI [-0.28, 0.86]). Neither the direct, 95\% CI [-0.17, 1.56], nor the indirect, $95 \%$ CI [-0.40, 0.88] effect of changes in mindfulness on changes in academic self-efficacy were statistically significant.

Given that changes in emotional wellbeing predicted changes in academic self-efficacy, correlation analysis was conducted showing that there was a significant positive correlation between the two variables, $r(13)=.66, p<.01$. Although changes in mindfulness did not significantly predict changes in academic self-efficacy in the model, the two variables did correlate significantly suggesting that there was a direct positive relationship present, $r(13)=.52$, $p=.049$. Changes in emotional wellbeing and changes in mindfulness did not correlate, $r(13)$ $=.29, p=.292$, indicating that the two constructs may be independently effecting academic selfefficacy.

Table 2: Mediation Analysis Examining Predictors of Change in Academic Self-Efficacy

\begin{tabular}{llll}
\hline Variable & $\mathrm{b}$ & LLCI & ULCI \\
\hline Constant & -0.50 & -7.45 & 6.46 \\
\cline { 1 - 1 } $\begin{array}{l}\text { Emotional Wellbeing } \\
\text { Change }\end{array}$ & $1.09 *$ & 0.22 & 1.95
\end{tabular}




\begin{tabular}{llll}
\cline { 1 - 2 } Mindfulness Change & 0.69 & -0.17 & 1.56 \\
\hline$R^{2}$ & .55 & & \\
\cline { 1 - 2 } & $7.26^{* *}$ & & \\
\hline$N$ & 15 &
\end{tabular}

Note. ${ }^{*}=\mathrm{p}<.05$, two-tailed. ${ }^{* *}=\mathrm{p}<.01$, two-tailed. LLCI $=$ Lower Limit Confidence Interval, ULCI $=$ Upper Limit Confidence Interval

\section{Discussion}

The purpose of this study was to examine the effect of a brief mindfulness intervention on academic self-efficacy and emotional wellbeing in university students. Measures of academic self-efficacy, mindfulness, emotional wellbeing and perceived social support were taken. A randomised controlled trial was conducted utilising two groups of university students. The experimental group completed a brief mindfulness intervention comprising four 30 minute mindfulness meditation sessions completed once per day for four consecutive days, the other group was a wait-listed control group and did not complete any intervention. Pre-, postintervention and one month follow-up measures were taken via online self-report surveys. It was predicted that, in the experimental group, as students' levels of mindfulness increased (due to the intervention), levels of academic self-efficacy would increase via a direct effect and an indirect effect with increased emotional wellbeing as the mediator.

Emotional wellbeing did significantly increase with a large effect size between the pre- and postintervention measures for the experimental group but not for the control group, supporting the hypothesised outcome. Emotional wellbeing seems to have been positively affected by the brief mindfulness intervention, an outcome that is supported by previous research (Baer et al., 2006; Brown \& Ryan, 2003; Carpenter, Sanford \& Hofmann, 2019; Sanchez-Alvarez et al., 2016; Walach et al., 2006).

Both academic self-efficacy and mindfulness increased for the experimental group between pre and post measures, while neither increase was statistically significant, both represent moderate effect sizes supporting the hypothesised outcomes. It may have been that the size of the experimental group $(\mathrm{N}=15)$ resulted in insufficient statistical power. Potentially a larger sample in a similarly designed experiment would give a statistically significant result. Mindfulness did increase significantly for the experimental group between the pre-intervention and one month follow-up while academic self-efficacy remained relatively unchanged from post-intervention to follow-up. The results indicated that the intervention lead to independent increases in both mindfulness and emotional wellbeing which both directly increased levels of academic selfefficacy, with emotional wellbeing having a larger effect. As such the hypothesised mediation model was not supported.

The present study sought to explore the gap in the literature with respect to maintenance of effects post-intervention via follow-up measures (Gallego et al., 2014). Interestingly at one month post-intervention, mindfulness had continued to increase and was significantly higher than baseline. This finding seems to suggest that the benefit of the intervention was lasting and that participants continued to experience its effects for at least one month. The finding that academic 
self-efficacy and emotional wellbeing remained at the elevated post-intervention level at followup additionally supports this suggestion.

Although academic self-efficacy did not significantly increase in the experimental group the effect found was moderate; as such regression analysis was carried out to explore the relationship between the variables. Although changes in mindfulness did have a significant positive correlation with changes in academic self-efficacy, changes in mindfulness did not independently predict at a statistically significant level either changes in academic self-efficacy or changes in emotional wellbeing. However, changes in emotional wellbeing did independently predict changes in academic self-efficacy with the two measures being highly positively correlated. This finding is predicted by self-efficacy theory (Bandura, 1977) in that improvements in the emotional state of participants correlated highly with increases in academic self-efficacy.

Perceived social support was included in preliminary data collection as there was some evidence in the literature that it may be a confounding variable in accurately measuring academic selfefficacy (Oliver et al., 2017; Reich et al., 2004). In the current sample, there was no correlation between measures of perceived social support and measures of academic self-efficacy and as such perceived social support was excluded from data analysis.

The effect size found for increased academic self-efficacy in the present study (0.472) is comparable to other successful forms of intervention with the same goal. An effect size of 0.45 was found after the use of a vicarious experience intervention (Bartsch et al., 2012) and an average effect size of $0.73,95 \%$ CI $[0.39,1.08]$, was found when reviewing 27 different studies utilising mastery experience interventions (self-assessments) (Panadero et al., 2017).

These results imply that a brief mindfulness intervention is effective and comparable to other successful interventions at increasing academic self-efficacy while additionally increasing mindfulness and emotional wellbeing. Furthermore these positive benefits seem to be maintained beyond the scope of the intervention. Given the significant beneficial effects of increased academic self-efficacy, mindfulness and increased emotional wellbeing in the context of a university student, including better academic achievement and motivation, improved mental health, enhanced career prospects, reduced stress and anxiety, higher future income and better physical health, (Baer et al., 2006; Bandura et al., 1996; Bracke et al., 2014; Brown \& Ryan, 2003; Chan, 2016; Chiesa \& Serretti, 2009; Chiu et al., 2016; Hahn \& Truman, 2015; Messer et al., 2016; Pradhan et al., 2007; Sanchez-Alvarez et al., 2016; Walach et al., 2006; Walsemann et al., 2013; Zautra et al., 2008), support for the methodology used in the present study in engendering these positive effects for students within a brief timeframe with minimal cost is meaningful. The findings give further backing to the benefit of providing mindfulness sessions and brief intervention opportunities to university students as a practical means of affording them better outcomes (Messer et al., 2016). Interestingly the findings suggest that the positive effect of a mindfulness intervention extends beyond the duration of the intervention which is significant given the lack of data in this area and warrants further investigation.

The strengths of the present study are that a control condition was included for comparison and that participants were randomised between the control and experimental conditions, thus better delineating changes attributable to the intervention as compared with changes caused by potential common confounding factors. Participants received course credit for participation in the study and therefore volunteers were not restricted to those who had a previous knowledge or 
interest in mindfulness, which may have introduced a confirmatory bias. The pre-intervention measures of mindfulness showed that there was no significant difference in baseline mindfulness between participants in the control and experimental group, therefore the two groups were comparable in this regard. This study utilised experienced mindfulness meditation facilitators to conduct the mindfulness sessions in-person with participants, as previous research has suggested that conducting a mindfulness intervention without an in-person facilitator may be less effective (Polak, 2009).

There were several weaknesses in the present study. Most notably the sample size obtained was relatively small and the methodology would benefit from a larger sample with twenty or more participants per group as was originally intended. Time limitations on the present study prevented further recruitment. Another weakness is that the construct of mindfulness is not well defined in the literature overall and even more significantly so when comparing the understanding of the general public and the definitions used in academia (Van Dam et al., 2018). There has been significant criticism of the overuse of self-report measures in the field of mindfulness because of this discrepancy, for example, some studies have found that experienced meditators were less mindful than binge drinkers (Grossman \& Van Dam, 2011; Leigh, Bowen \& Marlatt, 2005). This was hypothesised to be because experienced meditators had a better understanding of what mindfulness was and as such provided self-report answers that they felt were accurate by their own definition, which inherently differs from the definition held by unexperienced meditators (Van Dam et al., 2018). Addressing this issue was beyond the scope of the present study but finding more meaningful, accurate, valid and generalisable means of measuring and defining mindfulness is a critical area to focus on for future research in this field.

In the current study it is possible that the increase in self-reported mindfulness of participants in the experimental group was muted because participants had a better understanding of the concept of mindfulness after having actually engaged in mindfulness practice and thus at postintervention rated themselves more conservatively than they had at pre-intervention, prior to having this understanding. If more accurate and valid measures were available via methods other than self-report, a more significant effect may have been found - that is, without the interference of the participants' familiarity with what is entailed in being mindful having increased between pre- and post-measures as a result of participating in the intervention.

The present study focused on improving academic self-efficacy for university students, however brief mindfulness interventions could provide benefits to other groups across varying industries via increases in general or particularised forms of self-efficacy. Self-efficacy theory (Bandura, 1977) predicts that improvements in emotional state will lead to increased levels of self-efficacy; this prediction is supported by the present study. Further research could investigate if a brief mindfulness intervention has a similar positive effect in different populations. Future studies seeking to expand on the present findings should employ a larger sample as this would potentially lead to a more significant increase in academic self-efficacy and thus stronger data. Longer follow-up measure intervals would also be meaningful and further add to the understanding of the lasting effects of mindfulness practice beyond the period of the intervention. It was beyond the scope of the present study to investigate whether experimental participants continued to practice mindfulness meditation following the intervention. As such the mechanism by which a lasting positive effect of the intervention remained is unknown and merits investigation in future research. Additionally, comparing the effect of mindfulness practice, as 
operationalised in the present study, to active control conditions, which may also increase academic self-efficacy or mindfulness, would add strength to future research. More appropriate means of measuring and defining mindfulness as a construct would also benefit future studies seeking to expand on the present findings and any other research in the field of mindfulness.

The findings support the notion that a brief mindfulness intervention is an effective and practical method by which to better support university students by increasing their academic self-efficacy, mindfulness and emotional wellbeing. Further replication of these results in similar studies with larger samples is required and warranted given this form of support can seemingly make a meaningful positive difference to both students and institutions alike.

Author Contributions Both authors were involved in conceptualisation of the study and in selection of measures. The Brief Mindfulness intervention was facilitated by two staff from the James Cook University Wellness Centre. JM collected, analysed and interpreted the data. Both $\mathrm{JM}$ and MC contributed to the final written manuscript.

\section{Compliance with Ethical Standards}

Conflict of Interest The authors declare that they have no conflict of interest.

Ethical Approval. All procedures performed in this study involving human participants were in accordance with the ethical standards of the Human Research Ethics Committee of James Cook University and with the 1964 Helsinki declaration and its later amendments or comparable ethical standards.

Informed Consent Informed consent was obtained from all individual participants prior to participation in the study.

\section{References}

Andrews-Hanna, J. R., Kaiser, R. H., Turner, A. J. E., Reineberg, A. E., Godinez, D., Dimidjian, S., \& Banich, M. T. (2013). A penny for your thoughts: Dimensions of self-generated thought content and relationships with individual differences in emotional wellbeing. Frontiers in Psychology, 4, 1-13.

Baer, R. A., Smith, G. T., Hopkins, J., Krietemeyer, J., \& Toney, L. (2006). Using Self-Report Assessment Methods to Explore Facets of Mindfulness. Assessment, 13(1), 27-45.

Bandura, A. (1977). Self-efficacy: Toward a Unifying Theory of Behavioral Change. Psychological Review, 84, 191-215.

Bandura, A. (1999). Social Cognitive Theory: An Agentic Perspective. Asian Journal of Social Psychology, 2, 21-41.

Bandura, A., Barbaranelli, C., Caprara, G. V., \& Pastorelli, C. (2001). Self-Efficacy Beliefs as Shapers of Children's Aspirations and Career Trajectories. Child Development, 72(1), 187-206.

Bartsch, R. A., Case, K. A., \& Meerman, H. (2012). Increasing academic self-efficacy in statistics with a live vicarious experience presentation. Teaching of Psychology, 39(2), 133-136.

Blanck, P., Perleth, S., Heidenreich, T., Kröger, P., Ditzen, B., Bents, H., \& Mander, J. (2018). Effects of mindfulness exercises as stand-alone intervention on symptoms of anxiety and 
depression: Systematic review and meta-analysis. Behaviour Research and Therapy, 102, 25-35.

Bracke, P., Van De Straat, V., \& Missinne, S. (2014). Education, Mental Health, and EducationLabor Market Misfit. Journal of Health and Social Behavior, 55(4), 442-459.

Brown, K. W., \& Ryan, R. M. (2003). The Benefits of Being Present: Mindfulness and its Role in Psychological Well-Being. Journal of Personality and Social Psychology, 84(4), 822848.

Cambridge-Williams, T., Winsler, A., Kitsantas, A., \& Bernard, E. (2013). University 100 Orientation Courses and Living-Learning Communities Boost Academic Retention and Graduation via Enhanced Self-Efficacy and Self-Regulated Learning. Journal of College Student Retention: Research, Theory \& Practice, 15(2), 243-268.

Caprara, G. V., Fida, R., Vecchione, M., Del Bove, G., Vecchio, G. M., Barbaranelli, C., \& Bandura, A. (2008). Longitudinal Analysis of the Role of Perceived Self-Efficacy for Self-Regulated Learning in Academic Continuance and Achievement. Journal of Educational Psychology, 100(3), 525-534.

Carpenter, J., Sanford, J., \& Hofmann, S. (2019). The effect of a brief mindfulness training on distress tolerance and stress reactivity. Behavior Therapy, 50(3), 630-645.

Cervone, D. (2000). Thinking about Self-Efficacy. Behavior Modification, 24(1), 30-56.

Chambers, R., Gullone, E., \& Allen, N. B. (2009). Mindful emotion regulation: An integrative review. Clinical Psychology Review, 29(6), 560-572.

Chan, R. (2016). Understanding the purpose of higher education: An analysis of the economic and social benefits for completing a college degree. Journal of Education Policy, Planning and Administration, 6(5), 1-40.

Chiesa, A., \& Serretti, A. (2009). Mindfulness-Based Stress Reduction for Stress Management in Health People: A Review and Meta-Analysis. The Journal of Alternative and Complementary Medicine, 15(5), 593-600.

Chiu, C., Hayward, M., \& Saito, Y. (2016). A comparison of educational differences on physical health, mortality, and healthy life expectancy in Japan and the United States. Journal of Aging and Health, 28(7), 1256-1278.

Crescentini, C., \& Capurso, V. (2015). Mindfulness meditation and explicit and implicit indicators of personality and self-concept changes. Frontiers in Psychology, 6(44), 1-6.

Gallego, J., Aguilar-Parra, J. M., Cangas, A. J., Langer, A. I., \& Manas, I. (2014). Effect of a Mindfulness Program on Stress, Anxiety and Depression in University Students. Spanish Journal of Psychology, 17, 1-6.

Garland, E. L., Hanley, A. W., Baker, A. K., \& Howard, M. O. (2017). Biobehavioral Mechanisms of Mindfulness as a Treatment for Chronic Stress: An RDoC Perspective. Chronic Stress, 1, 1-14.

Grossman, P., \& Van Dam, N. T. (2011). Mindfulness, by any other name . . . : Trials and tribulations of sati in Western psychology and science. Contemporary Buddhism, 12, 219-239.

Haddock, G., Foad, C., Windsor-Shellard, B., Dummel, S., \& Adarves-Yorno, I. (2017). On the attitudinal consequences of being mindful: Links between mindfulness and attitudinal ambivalence. Personality and Social Psychology Bulletin, 43(4), 439-452.

Hahn, R. A., \& Truman, B. I. (2015). Education Improves Public Health and Promotes Health Equity. International Journal of Health Services, 45(4), 657-678. 
Hanley, A. W., Palejwala, M. H., Hanley, R. T., Canto, A. I., \& Garland, E. L. (2015). A failure in mind: Dispositional mindfulness and positive reappraisal as predictors of academic self-efficacy following failure. Personality and Individual Differences, 86, 332-337.

Harris, A., Jennings, P., Katz, D., Abenavoli, R., \& Greenberg, M. (2016). Promoting stress management and wellbeing in educators: Feasibility and efficacy of a school-based yoga and mindfulness intervention. Mindfulness, 7(1), 143-154.

Hodgins, H. S., \& Knee, C. R. (2002). The integrating self and conscious experience. In E. L. Deci \& R. M. Ryan (Eds.), Handbook of self-determination research (pp. 87-100). Rochester, NY: University of Rochester Press.

Honicke, T., \& Broadbent, J. (2016). The influence of academic self-efficacy on academic performance: A systematic review. Educational Research Review, 17, 63-84.

Kabat-Zinn, J. (1990). Full catastrophe living: How to cope with stress, pain and illness using mindfulness meditation. London, United Kingdon: Piatkus.

Leigh, J., Bowen, S., \& Marlatt, G. A. (2005). Spirituality, mindfulness, and substance abuse. Addictive Behaviors, 30, 1335-1341.

Messer, D., Horan, J. J., Turner, W., \& Weber, W. (2016). The Effects of Internet-Delivered Mindfulness Training on Stress, Copying and Mindfulness in University Students. AERA Open, 2(1), 1-8.

Mrazek, M. D., Franklin, M. S., Phillips, D. T., Baird, B., \& Schooler, J. W. (2013). Mindfulness training improves working memory capacity and GRE performance while reducing mind wandering. Psychological Science, 24(5), 776-781.

Oliver, D., Patil, S., Benson, J., Gage, A., Washington, K., Kruse, R., \& Demiris, G. (2017). The effect of internet group support for caregivers on social support, self-efficacy, and caregiver burden: A meta-analysis. Telemedicine and e-Health, 23(8), 621-629.

Panadero, E., Jonsson, A., \& Botella, J. (2017). Effects of self-assessment on self-regulated learning and self-efficacy: Four meta-analyses. Educational Research Review, 22, 74-98.

Palomino, M. D. P. (2017). An Analysis of Self-Concept in Students With Compensatory Education Needs for Developing a Mindfulness-Based Psychoeducational Program. SAGE Open, 1, 1-11.

Perry, J. C., DeWine, D. B., Duffy, R. D., \& Vance, K. S. (2007). The academic self-efficacy of urban youth: A mixed-methods study of a school-to-work program. Journal of Career Development, 34(2), 103-126.

Polak, E. L. (2009). Impact of Two Sessions of Mindfulness Training on Attention. (Unpublished doctoral dissertation, University of Miami, Florida, United States of America). Retrieved from https://pdfs.semanticscholar.org/b375/6c7900d80044072bdcb688c8c57745e89701.pdf

Pradhan, E. K., Baumgarten, M., Langenberg, P., Handwerger, B., Gilpin, A. K., Magyari, T., Hochberg, M. C., Berman, B. M. (2007). Effect of Mindfulness-Based Stress Reduction in Rheumatoid Arthritis Patients. Arthritis and Rheumatism, 57(7), 1134-1142.

Ramsburg, J. T., \& Youmans, R. J. (2014). Meditation in the higher-education classroom: Meditation training improves student knowledge retention during lectures. Mindfulness, 5(4), 431-441.

Rasmussen M. K., \& Pidgeon A. M. (2011). The direct and indirect benefits of dispositional mindfulness on self-esteem and social anxiety. Anxiety, Stress, \& Coping, 24(2), 227-233. 
Reich, S., Bickman, L., \& Heflinger, C. A. (2004). Covariates of Self-Efficacy: Caregiver Characteristics Related to Mental Health Services Self-Efficacy. Journal of Emotional and Behavioral Disorders, 12(2), 99-108.

Sampl, J., Maran, T., \& Furtner, M. R. (2017). A Randomized Controlled Pilot Intervention Study of a Mindfulness-Based Self-Leadership Training (MBSLT) on Stress and Performance. Mindfulness, 8(5), 1393-1407.

Sanchez-Alvarez, N., Extremera, N., \& Fernandez-Borrocal, P. (2016). The relationship between emotional intelligence and subjective well-being: A meta-analytic investigation. The Journal of Positive Psychology, 11(3), 276-285.

Schunk, D. H. (1991). Self-efficacy and academic motivation. Educational Psychologist, 26(34), 207-231.

Spedding, J., Hawkes, A. J., \& Burgess, M. (2017). Peer Assisted Study Sessions and Student Performance: The Role of Academic Engagement, Student Identity, and Statistics Selfefficacy. Psychology, Learning \& Teaching, 16(1), 144-163.

Splevins, K., Smith, A., \& Simpson, J. (2009). Do improvements in emotional distress correlate with becoming more mindful? A study of older adults. Aging and Mental Health, 13(3), 328-335.

Sulphey, M. M. (2016). Is mindfulness a predictor of locus of control? Journal of Applied Managements and Investments, 5(2), 121-130.

Tang, Y. Y., Ma, Y., Wang, J., Fan, Y., Feng, S., Lu, Q., ... Posner, M. I. (2007). Short-term meditation training improves attention and self-regulation. Proceeding of the National Academy of Science U S A, 104(43), 17152-17156.

Tennant, R., Hiller, L., Fishwick, R., Platt, S., Joseph, S., ... Stewart-Brown, S. (2007). The Warwick-Edinburgh Mental Well-Being Scale (WEMWBS): Development and UK validation. Health and Quality of Life Outcomes, 5(1), 1-13.

Unrau, N. J., Rueda, R., Son, E., Polanin, J. R., Lundeen R. J., \& Muraszewski, A. K. (2018). Can Reading Self-Efficacy Be Modified? A Meta-Analysis of the Impact of Interventions on Reading Self-Efficacy. Review of Educational Research, 88(2), 167-204.

Van Dam, N. T., van Vugt, M. K., Vago, D. R., Schmalzl, L., Saron, C. D., ... Meyer, D. E. (2018). Mind the hype: A critical evaluation and prescriptive agenda for research on mindfulness and meditation. Perspectives on Psychological Science, 13(1), 36-61.

Walach, H., Buchheld, N., Buttenmuller, V., Kleinknecht, N., \& Schmidt, S. (2006). Measuring mindfulness - the Freiburg Mindfulness Inventory (FMI). Personality and Individual Differences, 40(8), 1543-1555.

Walsemann, K. M., Gee, G. C., \& Ro, A. (2013). Educational Attainment in the Context of Social Inequality: New Directions for Research on Education and Health. American Behavioral Scientist, 57(8), 1082-1104.

Weinstein, N., Brown, K. W., \& Ryan, R. M. (2009). A multi-method examination of the effects of mindfulness on stress attribution, coping and, emotional well-being. Journal of Research in Personality, 43, 374-385.

Zajacova, A., Lynch, S. M., \& Espenshade, T. J. (2005). Self-efficacy, stress, and academic success in college. Research in Higher Education, 46(6), 677-706.

Zautra, A. J., Davis, M. C., Reich, J. W., Nicassario, P., Tennen, H., Finan, P., .. Irwin, M. R. (2008). Comparison of cognitive behavioral and mindfulness meditation interventions on adaptation to rheumatoid arthritis for patients with and without history of recurrent depression. Journal of Consulting and Clinical Psychology, 76(3), 408-421. 
Zimet, G. D., Dahlem, N. W., Zimet, S. G., \& Farley, G. K. (1988). The Multidimensional Scale of Perceived Social Support. Journal of Personality Assessment, 52(1), 30-41. 